University of Nebraska - Lincoln

DigitalCommons@University of Nebraska - Lincoln

Roman L. Hruska U.S. Meat Animal Research

U.S. Department of Agriculture: Agricultural Center

Research Service, Lincoln, Nebraska

2007

\title{
Placental Expression of the Membrane Form of Folate Binding Protein During Pregnancy in Swine
}

J. G. Kim

Louisiana State University Health Sciences Center-New Orleans

J. L. Vallet

USDA-ARS, Jeff.Vallet@ars.usda.gov

Follow this and additional works at: https://digitalcommons.unl.edu/hruskareports

Kim, J. G. and Vallet, J. L., "Placental Expression of the Membrane Form of Folate Binding Protein During Pregnancy in Swine" (2007). Roman L. Hruska U.S. Meat Animal Research Center. 257.

https://digitalcommons.unl.edu/hruskareports/257

This Article is brought to you for free and open access by the U.S. Department of Agriculture: Agricultural Research Service, Lincoln, Nebraska at DigitalCommons@University of Nebraska - Lincoln. It has been accepted for inclusion in Roman L. Hruska U.S. Meat Animal Research Center by an authorized administrator of DigitalCommons@University of Nebraska - Lincoln. 


\title{
Placental expression of the membrane form of folate binding protein during pregnancy in swine ${ }^{2 / 3}$
}

\author{
J.G. Kim ${ }^{1}$, J.L. Vallet* \\ United States Department of Agriculture, Agricultural Research Service, Roman L. Hruska U.S. Meat Animal Research Center, \\ P.O. Box 166, Clay Center, NE 68933-0166, United States
}

Received 7 July 2006; accepted 9 January 2007

\begin{abstract}
Previous experiments indicated that secreted (s) and membrane (m) forms of folate binding protein (FBP) are present in the intrauterine environment of the pig. Our previous studies indicated that the two forms were produced sequentially; the secreted form was present in the intrauterine glands until Day 20 of gestation, whereas binding analysis indicated that folate binding increased dramatically in placental membranes until Day 50 of gestation. However, the cell types expressing mFBP have not been investigated. In this experiment, uterine wall sections from Day 20,35, 50,70, 90, and 105 of gestation were collected at slaughter and fixed, and subjected to in situ hybridization analysis for mFBP expression. The mFBP mRNA was expressed by both columnar and cuboidal epithelia of the placental folds and expression appeared to be similar throughout gestation. Therefore, the placenta expressed mFBP from Day 35 of gestation onward, consistent with the concept that sFBP and mFBP occur sequentially during gestation in swine, and that placental mFBP expression plays a role in folate transport after a functional chorioallantoic placenta is established (between Day 20 and 35).
\end{abstract}

Published by Elsevier Inc.

Keywords: Folate; Placenta; Pregnancy; Swine; In situ hybridization

\section{Introduction}

Folate is required as a cofactor in the transfer of methyl groups, i.e. biochemical reactions which include thymidine synthesis [1]. Thus, folate is essential for cell division and growth [2], and deficiencies impair processes, e.g. erythropoiesis [3] and fetal development

\footnotetext{
Names are necessary to report factually on available data; however, the USDA neither guarantees nor warrants the standard of the product, and the use of the name by USDA implies no approval of the product to the exclusion of others that may also be suitable.

* Corresponding author. Tel.: +1 402762 4187;

fax: +14027624382 .

E-mail address: Jeff.Vallet@ars.usda.gov (J.L. Vallet).

${ }^{1}$ Present address: Department of Pathology, LSUHSC-NO, 533

Bolivar Street, CSRB 7-24, New Orleans, LA 70112, United States.
}

[4] where rapid cell division occurs. Secreted (s) and membrane $(\mathrm{m})$ forms of folate binding protein (FBP) were present in the intrauterine environment of the pig to deliver folate to the developing fetuses [5-9]. In more recent studies, it was reported that the two forms were produced sequentially during the 114-d gestation of the pig. The sFBP form increased dramatically in uterine flushings at the time of conceptus elongation (Day 1115) and was present in the intrauterine glands until Day 20 of gestation $[7,10]$. We have demonstrated that genetic polymorphisms in the sFBP gene were associated with differences in uterine capacity, but not litter size, because of simultaneous effects on ovulation rate [11]. Thus, other genes involved in folate transport during gestation are of interest as potential candidate genes for genetic markers associated with uterine capacity and litter size. Placental membrane 
folate binding increased dramatically until Day 50 of gestation [10]. However, two membrane forms of FBP are known in swine, one intrauterine [8] and one isolated from the liver [12], thus, we could not determine whether the intrauterine form of $\mathrm{mFBP}$ previously described [8] contributed to placental membrane folate binding during pregnancy. The measurement of folate binding reported previously did not distinguish between the two membrane forms. Further associations between variation in the genes responsible for folate transport and uterine capacity and litter size require the identification of the genes involved in folate transport during pregnancy. In addition, placental cell types expressing mFBP have not been investigated. Identification of the cell types responsible are needed to fully understand the role of various tissues in folate transport during pregnancy. Thus, our objective was to confirm that the intrauterine membrane form of FBP that we described previously was expressed during pregnancy and to determine the cells expressing mFBP in the uterus and placenta throughout gestation.

\section{Materials and methods}

Unless otherwise indicated, all chemicals used were purchased from Sigma-Aldrich (St. Louis, MO, USA). All gilts in this experiment were fed a standard swine diet that met the NRC recommendations for folate. Estrus detection was performed using intact boars beginning at approximately $200 \mathrm{~d}$ of age. White composite gilts were mated at standing estrus (Day $0)$ or remained not pregnant. Gilts were slaughtered on Day 10, 13 and 15 of the estrous cycle $(n=4,3,3$, respectively) or pregnancy ( $n=3,3,6$, respectively), and on Day $20(n=3), 35(n=4), 50(n=5), 70(n=3)$, $90(n=5)$, and $105(n=3)$ of pregnancy. For gilts killed from Day 10 to 15 of the cycle or pregnancy, the uterus was flushed with $20 \mathrm{~mL}$ Minimal Essential Medium to collect uterine flushings and confirm pregnancy. Pregnancy was confirmed by the presence of conceptus tissue of normal appearance. For all gilts, a section of uterine wall was collected and fixed with $4 \%$ paraformaldehyde in PBS. After $16 \mathrm{~h}$, fixed tissues were washed with PBS $(2 \times 1 \mathrm{~h})$, dehydrated through a graded series of ethanol concentrations followed by three changes of xylene, incubated in two changes of paraffin $\left(60{ }^{\circ} \mathrm{C}\right)$, and were embedded in paraffin [10]. In situ hybridization was performed essentially as described by Spencer et al. [13]. Sections were cut $(6 \mu \mathrm{m})$, placed on slides, deparaffinized in xylene, and then rehydrated to water through a graded series of ethanol concentrations. Slides were then incubated with
Proteinase $\mathrm{K}(20 \mu \mathrm{g} / \mathrm{mL})$ for $8 \mathrm{~min}$ at $37{ }^{\circ} \mathrm{C}$, rinsed twice for $5 \mathrm{~min}$ each in PBS, and then hybridization solution containing radiolabeled cRNA probes $\left(5 \times 10^{6} \mathrm{cpm} / \mathrm{slide}\right)$ was applied to each slide and coverslipped. The mFBP probe used was based on the previously reported intrauterine $\mathrm{mFBP}$ cDNA sequence [8]. A 117-bp fragment of the $3^{\prime}$ end of the mFBP cDNA that was $35 \%$ identical to the same region of the sFBP cDNA, $47 \%$ identical to porcine liver mFBP [12] and that was previously shown to distinguish between sFBP and intrauterine mFBP cDNAs [8], was used as template to synthesize cRNA probes. Tissue specificity of the mFBP probe was reported previously; this probe did not hybridize to RNA from pig liver [8], clearly indicating that it did not cross-hybridize with the pig liver form of mFBP. Antisense and sense cRNA probes were generated using T7 and SP6 RNA polymerases (Maxiscript RNA synthesis kit, Ambion, Austin, TX, USA), respectively, from a linearized porcine mFBP plasmid template in the presence of ${ }^{35} \mathrm{~S}$-labeled UTP (specific activity, $3000 \mathrm{Ci} / \mathrm{mmol}$; GE Healthcare, Piscataway, NJ, USA). Slides were incubated in a humidified chamber and hybridized overnight at $55^{\circ} \mathrm{C}$. Slides were washed and incubated with DNase-free RNase $(10 \mu \mathrm{g} / \mathrm{mL})$. Sections were dehydrated through a graded series of ethanol and xylene, dried, and dipped in Kodak NTB2 emulsion (Eastman Kodak, Rochester, NY, USA). Slides were allowed to dry and were then exposed for 2 weeks, developed, and counterstained with Harris' modified hematoxylin in acetic acid (Fisher, Fairlawn, NJ, USA). Slides were visually appraised for specific labeling by comparison of silver grain density of antisense and sense probe labeled slides. Because in situ hybridization is not quantitative, particularly when probes labeled in different reactions are used as they were here, no attempt was made to quantify silver grain densities. Within each batch of slides, tissue sections from Day 35 of pregnancy or later were included to ensure that hybridizations were successful (these served as positive controls for the in situ hybridization technique; in each batch, specific labeling above the placental epithelium was evident).

\section{Results}

No convincing evidence of specific labeling for mFBP mRNA was observed in endometrial stromal cells and endometrial epithelia during the estrous cycle or pregnancy (Figs. 1 and 2) in any gilts examined in this experiment. In contrast, mFBP mRNA was expressed by chorionic epithelia (Fig. 3a), including both columnar and cuboidal forms in all gilts examined 


\section{Cyclic}

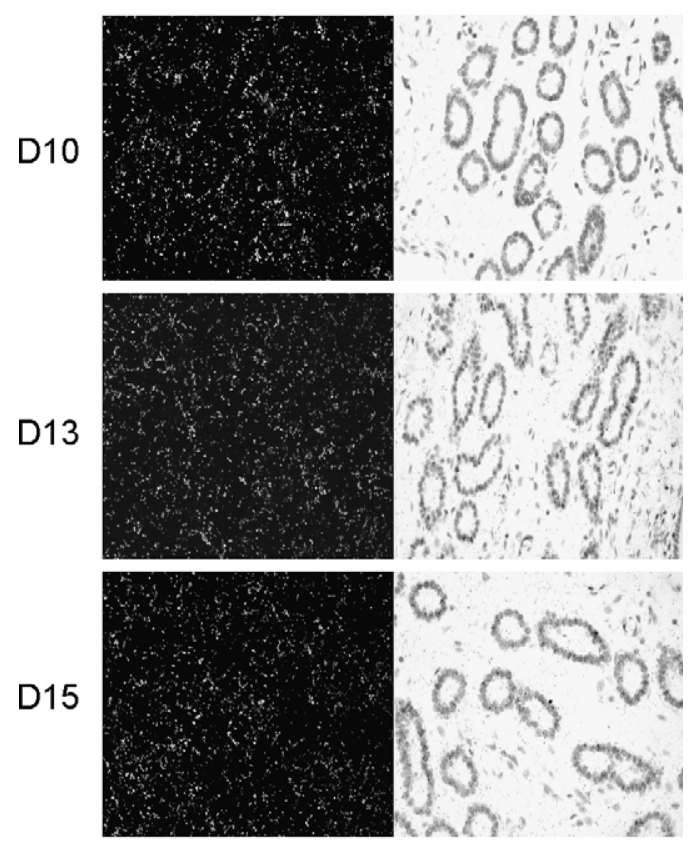

\section{Pregnant}

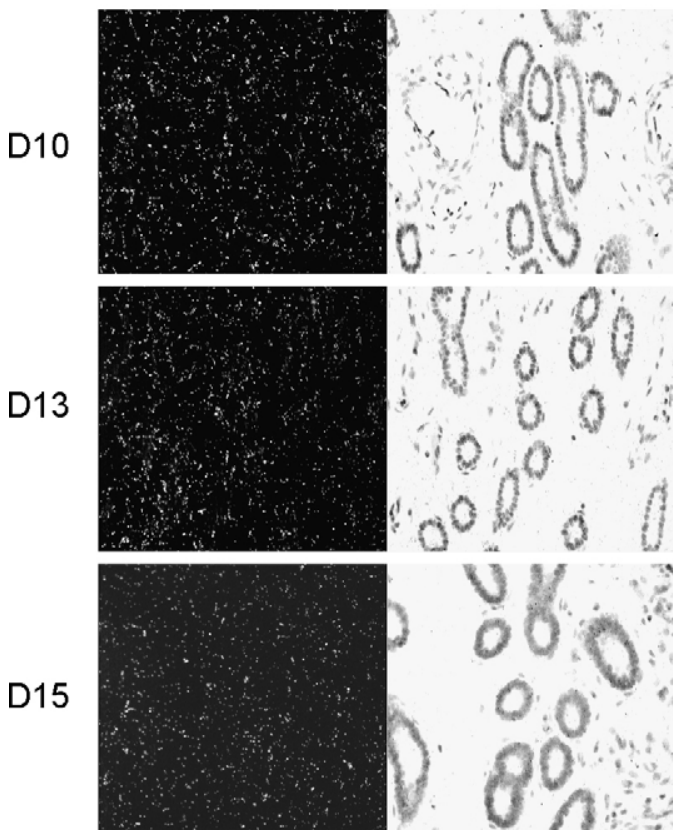

Fig. 1. Localization of expression of the membrane form of folate binding protein $(\mathrm{mFBP})$ during the estrous cycle and pregnancy in endometrial glands in pigs. No differences were observed in the abundance of silver grains over the endometrial glands between antisense (AS) and sense (S) probes (sense probe hybridizations not shown; see Figs. 2 and 3 for representative sense probe labeling).

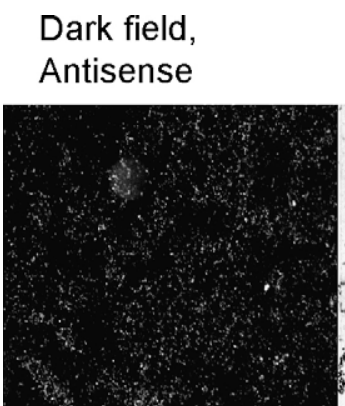

Dark field,

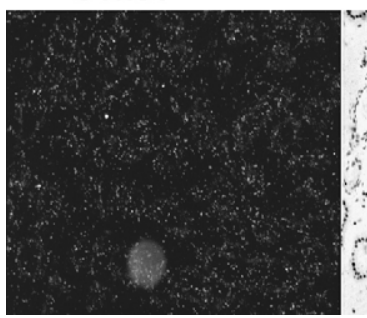
Sense
Bright field, Antisense

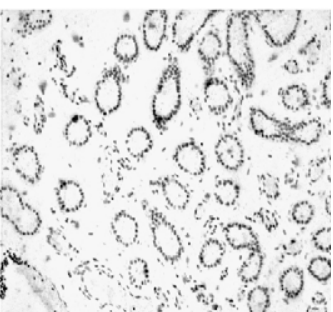

Bright field, Sense

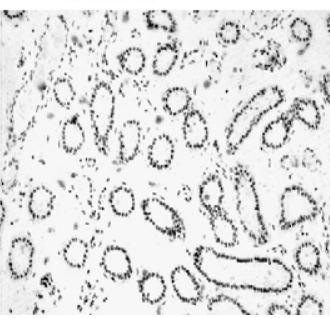

Fig. 2. In situ hybridization analysis of a uterine wall section from Day 50 of gestation in pigs for the membrane form of folate binding protein (mFBP) using antisense and sense probes. An area including the endometrial glands is shown using both dark and bright-field microscopy. No specific labeling above the endometrial gland cells was observed in the antisense probe compared to the sense-treated slides.

between Day 35 and 105 of gestation (Fig. 4). Although the in situ hybridizations presented here were not quantitative due to hybridization with different probe batches, expression was consistently evident in all placentae from Day 35 to 105 .

\section{Discussion}

In situ hybridization analysis indicated that mFBP was expressed primarily in the chorionic epithelia from Day 20 of gestation onward. No convincing evidence of specific labeling for the intrauterine form of $\mathrm{mFBP}$ was obtained for any endometrial cell type during the estrous cycle or pregnancy. These results were consistent with our previous findings that placental folate binding was present from Day 35 of pregnancy [10] and that mFBP mRNA was present in the placenta on Day 30 of pregnancy, as measured by Northern blot analysis [8]. However, results of the present study were not consistent with those from previous experiments that indicated that mFBP mRNA was expressed by the endometrium during the estrous cycle and early pregnancy [8].

The lack of homology between the region of the mFBP cDNA used as probe compared to the other 
(a)

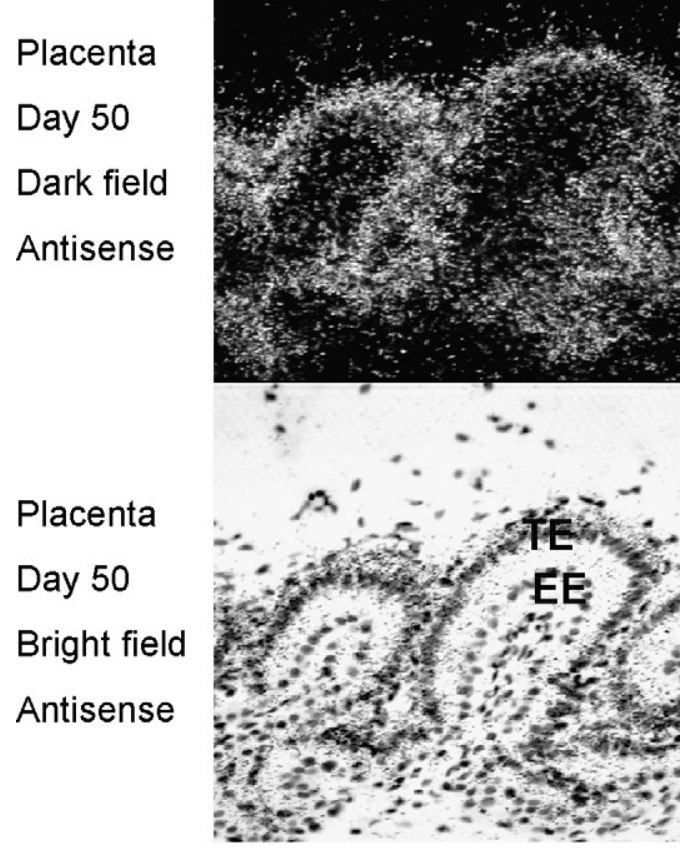

(b)

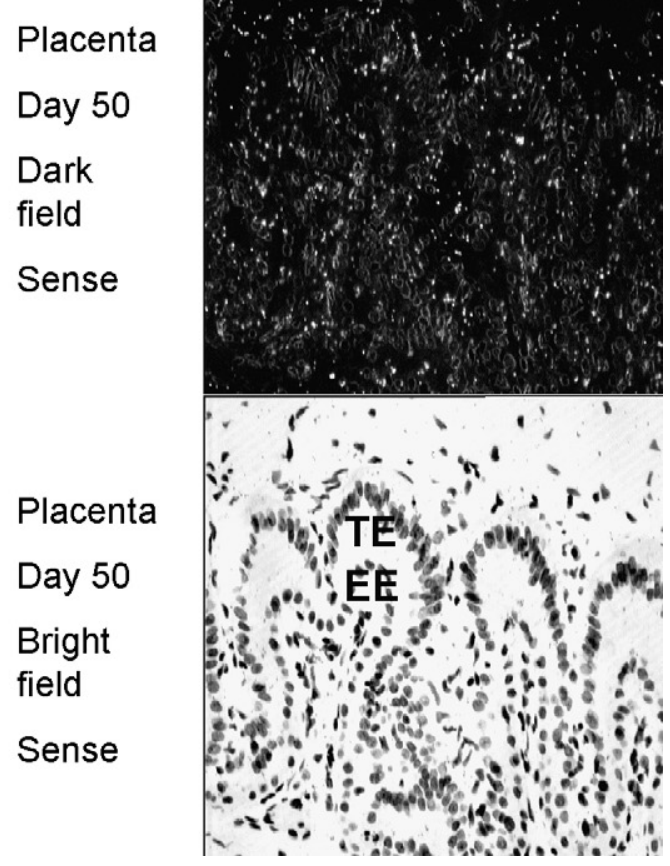

Fig. 3. In situ hybridization analysis of a uterine wall section from Day 50 of gestation in pigs for the membrane form of folate binding protein (mFBP) using antisense (a) and sense probes (b). An area including the placental and endometrial epithelium is shown using both dark and bright-field microscopy. More abundant silver grains were clearly and uniformly evident over the trophoblast epithelium (TE) compared to endometrial epithelium (EE) when sections were incubated with antisense compared with sense probe.
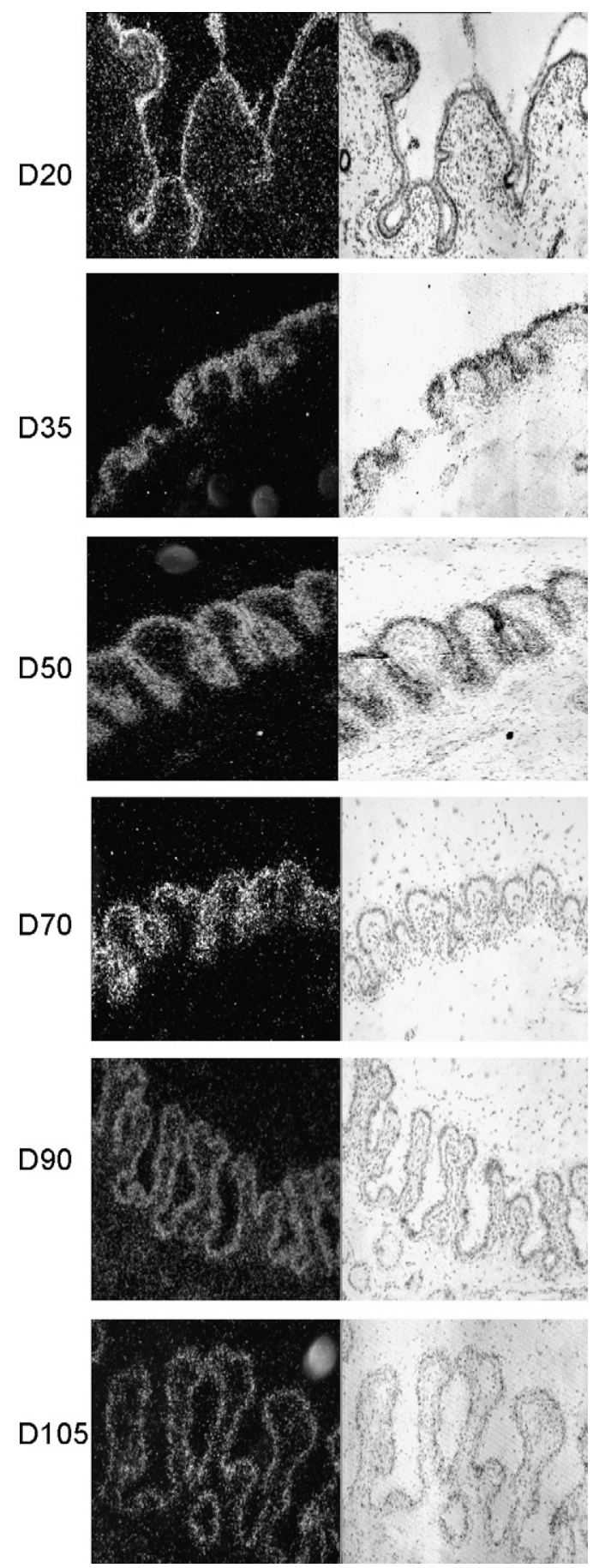

Fig. 4. In situ hybridization analyses for the membrane form of folate binding protein (mFBP) of uterine wall sections collected throughout gestation in pigs. Silver grains were more abundant over the placental epithelium, including both the tall columnar epithelium at the top of placental folds and the cuboidal epithelium present in the sides and bottom of placental folds. Although in situ analysis is not quantitative, the strength of labeling over the placental epithelium appeared to be uniform throughout gestation from Day 20 to 105 . 
known forms of FBP, combined with differential patterns of expression of the different forms in various tissues $[8,12]$, indicated that cross-hybridization of our $\mathrm{mFBP}$ probe with related forms of folate binding proteins did not occur. Our previous sFBP immunohistochemistry results clearly indicated the presence of sFBP up to Day 20 of pregnancy in the endometrial glands [10] and radioimmunoassay measurements and western blotting both indicated a dramatic increase in sFBP in uterine flushings [6,7]. This suggested the hypothesis that $\mathrm{mFBP}$ provided folate to endometrial gland cells for binding to the newly synthesized secreted form, which would then be secreted into the intrauterine environment. Thus, our failure to detect mFBP mRNA in the endometrium of pigs during the estrous cycle and pregnancy was surprising. Northern analysis for mFBP reported previously provided very light bands during the estrous cycle and pregnancy, with a convincing band present only for Day 15 pregnant endometrial tissue, and a very strong band from endometrium on Day 30 of pregnancy [8]. The discrepancy on Day 15 and 30 of pregnancy between the current experiment compared to previous results may be explained by contamination of endometrial tissue with conceptus tissue in our previous study. Superficial adhesion of conceptus tissue to the endometrium begins on Day 13 of gestation; therefore, endometrial tissue could remain contaminated with conceptus tissues despite flushing (Day 15) and careful dissection (Day 30) [14]. Another possibility that explains the lack of specific labeling during the estrous cycle and early pregnancy may be that the level of expression of mFBP was too low and too dispersed in the endometrium during the estrous cycle and early pregnancy to localize using our in situ hybridization methods. Given that intrauterine mFBP cannot be localized to the endometrial glands, an alternative hypothesis might be that the liver form of mFBP [12], which has never been examined in the intrauterine environment, could deliver folate to the endometrial glands. However, a further possibility is that the sFBP that is present in uterine flushings and endometrial glands is not a product of the glands themselves and instead might originate from serum. Endometrial expression of mRNA for sFBP does not change from Day 10 to 40 of pregnancy [8], despite dramatic increases in sFBP protein in uterine flushings $[6,7]$ and clear immunohistochemical staining of endometrial glands for sFBP from Day 13 to 20 of pregnancy, which disappears by Day 35 [10]. We have also been unable to demonstrate de novo production of sFBP by endometrial explants in culture in the presence of 35S-methionine (Kim and Vallet, unpub- lished observations), further suggesting that the sFBP in uterine flushings is not produced by endometrium. We recently demonstrated that many serum proteins were present in high concentrations in uterine flushings during this period [15]. Unfortunately, comparison between serum and uterine flush FBP did not provide much insight into whether uterine flush FBP originated from serum. Unlike uterine flush FBP, which is known to correspond to the secreted form, we are unaware of a similar amino acid sequence analysis of porcine serum FBP. Serum FBP could originate from any of the known porcine forms of FBP, as phospholipases are capable of liberating membrane forms of FBP. Comparison of binding affinities are not helpful because uterine flush [6,10], porcine serum [16] and placental membrane [10] forms of FBP all have approximately similar binding affinities (Kd.1-.5 nM). In addition, the binding affinity of porcine serum FBP changes depending on the surrounding lipid environment [10], which is likely to differ substantially between serum and the uterine lumen. The origin of sFBP in uterine flushings is beyond the scope of these experiments and requires further research.

We provided clear evidence that the intrauterine form of mFBP was expressed by the pig placenta throughout most of gestation, consistent with the previously proposed concept that sFBP was secreted by uterine glands until formation of the placenta and placental mFBP expression took over folate transport during later gestation in swine [10]. Therefore, expression of mFBP was at least partially responsible for the placental cell membrane folate binding measured in our previous report. However, it did not preclude a contribution from the other known form of mFBP [12], which is beyond the scope of this paper and will require further experimentation. Furthermore, based on in situ hybridization analysis, all placental epithelial cells expressed mFBP, including the tall columnar cells at the apices and the cuboidal cells on the sides and nadirs of the placental folds. Differences in the morphology of these cells suggested different functions. Friess et al. [17] suggested that the tall columnar epithelial cells were specifically responsible for the transfer of substrates from the dam to the fetus. The observation that all the placental epithelial cells expressed mFBP uniformly was not consistent with this concept, although the tall columnar epithelial cells may participate in the specific transfer of other substrates, in addition to folate. The role of the placental tall columnar epithelial cells in placental function requires further investigation.

In conclusion, we demonstrated that the pig placenta expressed the intrauterine form of $\mathrm{mFBP}$ throughout most of gestation, consistent with a role for $\mathrm{mFBP}$ in 
folate transport after the development of the placenta between Day 20 and 30 of pregnancy. We were unable to demonstrate specific expression of mFBP mRNA in endometrial cells at any stage of the cycle or pregnancy, in contrast to previous results demonstrating endometrial expression of mFBP by Northern blotting. This discrepancy was likely to be due to contamination of endometrial tissue by conceptus tissue caused by adhesion of conceptus tissue to the endometrial surface during pregnancy.

\section{Acknowledgements}

The authors thank S. Paus for technical help during this experiment and L. Parnell for secretarial assistance in the preparation of the manuscript. This project was supported by National Research Initiative Competitive Grant No. 2001-35203-11241 from the USDA Cooperative State Research, Education, and Extension Service.

\section{References}

[1] Shane B, Stokstad ELR. Vitamin B12-folate interrelationships. Annu Rev Nutr 1985;5:115-41.

[2] Blount BC, Mack MM, Wehr CM, MacGregor JT, Hiatt RA, Wang G, et al. Folate deficiency causes uracil misincorporation into human DNA and chromosome breakage: Implications for cancer and neuronal damage. Proc Natl Acad Sci USA 1997;94:3290-5.

[3] Babior BM. Erythrocyte disorders: anemias related to disturbances of DNA synthesis (megaloblastic anemias). In: Williams WJ, Beutler E, Erslev AJ, Lichtman MA, editors. Hematology. New York: McGraw-Hill; 1990. p. 453-81.

[4] Thenen SW. Gestational and neonatal folate deficiency in rats. Nutr Res 1991;11:105-16.

[5] Matte JJ, Girard CL, Brisson GJ. Folic acid and reproductive performances of sows. J Anim Sci 1984;59:1020-5.
[6] Vallet JL, Christenson RK, Klemcke HG. Purification and characterization of intrauterine folate-binding proteins from swine. Biol Reprod 1998;59:176-81.

[7] Vallet JL, Christenson RK, Klemcke HG. Technical note: a radioimmunoassay for porcine intrauterine folate binding protein. J Anim Sci 1999;77:1236-40.

[8] Vallet JL, Smith TPL, Sonstegard T, Pearson PL, Christenson RK, Klemcke HG. Isolation of complementary deoxyribonucleic acids encoding putative secreted and membrane-bound folate binding proteins from endometrium of swine. Biol Reprod 1999;61:372-9.

[9] Vallet JL, Smith TPL, Sonstegard TS, Heaton M, Fahrenkrug SC. Structure of the genes for porcine endometrial secreted and membrane folate binding proteins. Domest Anim Endocrinol 2001;21:55-72.

[10] Kim JG, Vallet JL. Secreted and placental membrane forms of folate-binding protein occur sequentially during pregnancy in swine. Biol Reprod 2004;71:1214-9.

[11] Vallet JL, Freking BA, Leymaster KA, Christenson RK. Allelic variation in the secreted folate binding protein gene is associated with uterine capacity in swine. J Anim Sci 2005;83:1860-7.

[12] Van Hoozen CM, Ling EH, Halsted CH. Folate binding protein: molecular characterization and transcript distribution in pig liver, kidney and jejunum. Biochem J 1996;319(Pt 3):725-9.

[13] Spencer TE, Ing NH, Ott TL, Mayes JS, Becker WC, Watson $\mathrm{GH}$, et al. Intrauterine injection of ovine interferon-tau alters oestrogen receptor and oxytocin receptor expression in the endometrium of cyclic ewes. J Mol Endocrinol 1995;15:203-20.

[14] Keys JL, King GJ. Microscopic examination of porcine conceptus-maternal interface between days 10 and 19 of pregnancy. Am J Anat 1990;188:221-38.

[15] Kayser J-PR, Kim JG, Cerny RL, Vallet JL. Global characterization of porcine intrauterine proteins during early pregnancy. Reproduction 2006;131:379-88.

[16] Holm J, Hansen SI. Characterization of a high affinity folate binding protein in porcine serum: ionic charge, concentrationdependent polymerization and ligand binding mechanism. Biosci Rep 2003;23:339-51.

[17] Friess AE, Sinowatz F, Skolek-Winnisch R, Traautner W. The placenta of the pig. I: Fine structural changes of the placental barrier during pregnancy. Anat Embryol (Berl) 1980;158:17991. 